STUDI

FRANCESI

\section{Studi Francesi}

Rivista quadrimestrale fondata da Franco Simone

184 (LXII | I) | 2018

Varia

\title{
RUTH AMAR, Quête et représentation du bonheur dans le roman français contemporain
}

\section{Francesca Lorandini}

\section{OpenEdition}

\section{Journals}

\section{Edizione digitale}

URL: https://journals.openedition.org/studifrancesi/12478

DOI: 10.4000/studifrancesi. 12478

ISSN: 2421-5856

\section{Editore}

Rosenberg \& Sellier

\section{Edizione cartacea}

Data di pubblicazione: 1 avril 2018

Paginazione: 171

ISSN: 0039-2944

Notizia bibliografica digitale

Francesca Lorandini, «RUTH AMAR, Quête et représentation du bonheur dans le roman français contemporain», Studi Francesi [Online], 184 (LXII | I) | 2018, online dal 04 juillet 2018, consultato il 17 novembre 2021. URL: http://journals.openedition.org/studifrancesi/12478 ; DOI: https://doi.org/ 10.4000/studifrancesi. 12478

Questo documento è stato generato automaticamente il 17 novembre 2021.

\section{(c) (i) () $\Theta$}

Studi Francesi è distribuita con Licenza Creative Commons Attribuzione - Non commerciale - Non opere derivate 4.0 Internazionale. 


\title{
RUTH AMAR, Quête et représentation du bonheur dans le roman français contemporain
}

\author{
Francesca Lorandini
}

\section{NOTIZIA}

RUTH AMAR, Quête et représentation du bonheur dans le roman français contemporain, Paris, Classiques Garnier, 2016, 297 pp.

1 L'analisi di Ruth Amar prende le mosse da una doppia domanda: quale idea di felicità viene veicolata dalla letteratura francese del secondo Novecento e con quali strategie narrative e procedimenti stilistici questa idea prende forma? Fin dalle prime pagine appare evidente che la felicità nella letteratura postmoderna non coincide necessariamente con un ideale da perseguire, ma si tratta di una nozione che deve fare sistematicamente i conti con la sfiducia nell'uomo determinata dal massacro della seconda guerra mondiale e con «l'ideologia egualitaria del benessere» (Baudrillard) che inizia a imporsi negli anni Sessanta. L'impressione è che i romanzieri francesi, per parlarne, si siano trovati a dover scegliere tra due possibilità: demistificare l'ingiunzione alla felicità che fonda la società dei consumi o suggerire una felicità alternativa, che non sia tirannica e euforizzante, ma semplice, intima, ordinaria.

Il libro è diviso in quattro parti, che indagano quattro manifestazioni possibili della ricerca della felicità come fatto culturale. «Le problème des passions et le bonheur conjugal» (pp. 31-109) si concentra sul rapporto tra amore e felicità di coppia nei romanzi di Christiane Rochefort, Pascal Bruckner, Éric Holder, Michèle Gazier e Jacqueline Harpman. Analizzando i toni narrativi, le tecniche della diegesi, la costruzione dei personaggi, Ruth Amar mostra come in questi romanzi il tema della felicità coniugale (che sia derisa, negata, riconosciuta o perseguita in modi utopici e trasgressivi) si intrecci inevitabilmente con altre questioni sociali, politiche e culturali 
che hanno segnato il secondo Novecento, come il femminismo, la liberazione dei costumi, l'esaltazione della passione e del desiderio nella società dei consumi e dello spettacolo. «Le bonheur au troisième âge» (pp. 111-183) indaga le rappresentazioni del «bien vieillir» in quattro romanzi: si passa dall'accettazione serena della senescenza di La marche lente des glaciers (Marie Rouanet) alla felicità individuale distinta dalla morale sociale di Le merle bleu (Michèle Gazier) e si arriva ad Anchise di Maryline Desbiolles e a La dernière leçon di Noëlle Châtelet, in cui la possibilità del suicidio è raccontata come forma ultima di affrancamento. «Le bonheur au quotidien» (pp. 185-228) si occupa di tre «minimalistes positifs» (la definizione è qui ripresa da Vincent Engel): Christian Bobin e i rapporti che intesse tra etica, fede e contemplazione; Philippe Delerm e la sua riflessione sull'angoscia che sembra inevitabilmente accompagnare la felicità; Pierre Michon e l'intensità sacrale della sua rappresentazione della realtà. "Vaincre le malaise. La possibilité du bonheur dans l'ère du vide» (pp. 229-274) si concentra infine sulla ricerca della felicità nell'opera di Jean-Marie Gustave Le Clézio e di Michel Houellebecq. Per Le Clézio la felicità non può che trovarsi nel rapporto solitario dell'uomo con la natura e nel ritorno al mondo avventuroso dell'infanzia. Benché per Houellebecq la felicità non sia un orizzonte di questo mondo (si pensi al ruolo che hanno nella sua opera la rivoluzione genetica e il Nirvana buddhista), nei suoi romanzi tornano con particolare insistenza tre temi, che permettono di intravedere la ricerca di una felicità ispirata agli scritti di Auguste Comte e Arthur Schopenhauer: il senso del dovere (in opposizione alle passioni), la ricerca di sé e l'amore (legato alla bontà e alla pietà). 